\title{
A Novel Method to Mitigate the Multipath Error for BDS-2 Dam Deformation Monitoring
}

\author{
Xuan Zou ${ }^{1}$, Zhiyuan Li $^{1}$, Yangyang Li $^{1, *}$, Yawei Wang ${ }^{1}$, Weiming Tang ${ }^{1,2} \mathbb{D}$, Chenlong Deng ${ }^{1} \mathbb{D}$, Jianhui Cui $^{3}$ \\ and Ruinan $\mathrm{Fu}^{1}$
}

1 GNSS Research Center, Wuhan University, 129 Luoyu Road, Wuhan 430079, China; zxuan@whu.edu.cn (X.Z.); lzyuan@whu.edu.cn (Z.L.); grcwongyw2016@whu.edu.cn (Y.W.); wmtang@whu.edu.cn (W.T.); c.deng@whu.edu.cn (C.D.); $2020206180029 @ w h u . e d u . c n$ (R.F.)

2 Collaborative Innovation Center of Geospatial Technology, 129 Luoyu Road, Wuhan 430079, China

3 College of Geodesy and Geomatics, Shandong University of Science and Technology, Qingdao 266590, China; jhcui@sdust.edu.cn

* Correspondence: yyangli@whu.edu.cn

Citation: Zou, X.; Li, Z.; Li, Y.; Wang, Y.; Tang, W.; Deng, C.; Cui, J.; Fu, R. A Novel Method to Mitigate the Multipath Error for BDS-2 Dam Deformation Monitoring. Remote Sens. 2021, 13, 1787. https://doi.org/ $10.3390 /$ rs13091787

Academic Editor: João

Catalão Fernandes

Received: 19 March 2021

Accepted: 27 April 2021

Published: 4 May 2021

Publisher's Note: MDPI stays neutral with regard to jurisdictional claims in published maps and institutional affiliations.

Copyright: (c) 2021 by the authors. Licensee MDPI, Basel, Switzerland. This article is an open access article distributed under the terms and conditions of the Creative Commons Attribution (CC BY) license (https:/ / creativecommons.org/licenses/by/ $4.0 /)$.

\begin{abstract}
The multipath effect on carrier-phase observations is related to the observational environment of the station, and cannot be eliminated or attenuated by the differential method. In the actual dam environment of deformation monitoring, multipath is very complicated. It is the main error source of BDS-2 for high precision data processing. In this paper, a new method called the multi-point hemispherical grid model (MHGM) is studied and evaluated. This method uses the hemispheric grid model to attenuate the influence of multipath errors. The effectiveness and improvement of the new method with respect to the popular sidereal filter (SF) method were assessed and verified by the actual dam monitoring data with only the BDS-2. The MHGM and SF approach calculates the multipath corrections from multi-days historical data, and then corrects the multipath error from the observations on the day of interest. Compared with the SF method, the MHGM can also effectively provide a graphical display of multipath error interference around the stations, which matches the surrounding observation environment. The results show that the double-differenced (DD) residuals of the MHGM for GEO/IGSO and MEO satellites are slightly better than those of SF, but the RMS of MHGM for GEO/IGSO+MEO DD residuals is improved by about $17.0 \%$. The performance of the MHGM method for different satellite constellations is consistent and not affected by the different orbital repeat times, which could solve the "zero mean" assumption problem of the SF method. Meanwhile, the RMS of static with a $2 \mathrm{~h}$ interval and kinematic positioning errors of the MHGM method in the horizontal and vertical direction can be up to 1.7, 3.6 and 2.4, $8.1 \mathrm{~mm}$, respectively. The MHGM model could avoid the multipath reference problem caused by different orbital repetition periods, making it more suitable for the combined multipath modeling of BDS-2 and BDS-3.
\end{abstract}

Keywords: deformation monitoring; BDS-2; multipath error; multi-point hemispherical grid model; sidereal filter

\section{Introduction}

Multipath is a major error source that affects the accuracy and reliability of GNSS data processing. Multipath error is defined as the total impact of the direct and the reflected signal of GNSS satellite arriving at the receiving antenna, which is usually caused by diffuse and specular reflection. The diffuse multipath generated by the reflection signal on the rough surface is not related with time and has behavior similar to noise [1,2]. However, specular multipath from a smooth reflecting surface can cause system errors, for which the maximum value for the carrier phase can be as high as $1 / 4$ wavelength [3]. Many studies have shown that multipath can be mixed into other parameters, such as position, tropospheric parameters and float ambiguity. Multipath effects cannot be simply averaged 
out over a limited period of data, and probably induce spurious deformation signals as well as bias the displacement estimations.

In addition to improving the observation environment and reducing reflection, multipath error could be also mitigated and reduced using hardware and software methods. Hardware methods mainly use the suppression board to attenuate the multipath, which is widely used but has high cost [4]. Software strategies are often used in high precision applications, such as weighting GNSS observation based on signal-to-ratio or satellite elevation angle $[5,6]$, employing filter methods to extract and mitigate multipath error. Filter methods have included finite impulse response (FIR) filter [7], wavelet analysis [8,9], Vondrak Filter with cross validation [10], adaptive filtering [11,12], and rotating antennas [13]. These methods can reduce the influence of multipath to a certain extent, but the interference of other random noise limits their effectiveness.

Currently, sidereal filtering (SF) is a widely used method to mitigate multipath error $[14,15]$. Based on the assumption that when the spatial relationship between the antenna and the observation environment remains unchanged, the SF method assumes that the multipath error of the station should mainly depend on the change of the signal propagation direction. Therefore, through the spatial relationship between the satellites and the station, the multipath error could be determined by the repetition of each sidereal day, then the observation of the following days can be corrected to reduce its impact [16-18]. The multipath error for the SF method is extracted from the coordinate sequence for correction of positioning results on subsequent sidereal days as well as observation domain. Alber et al. (2000) proposed a method to isolate the multipath effect by transforming double-differenced residuals to improve precipitable water vapor (PWV) [19]. Ragheb et al. (2007) found that the SF method based on the coordinate domain was more computationally efficient, but the observation domain was more accurate [20]. Based on a short baseline of SF correction observation, Zhong et al. (2010) obtained better positioning results than those with corrections in the coordinate domain [21]. The SF method can correct multipath to a certain extent. However, when the interval between the first day and subsequent days increases, the degree of repeatability will decrease. When the degree is reduced to a low value, the SF method is not able to effectively attenuate the multipath error.

Therefore, as with modeling multipath in coordinate domain or observation domain, modeling multipath in space domain (sky grid of orbit trace) can effectively mitigate its impact based on the repeatability of the satellite orbit period. Based on the assumption of "zero mean", Moore et al. (2014) proposed an empirical site model (ESM) to mitigate the unmodelled site-specific errors [22]. A site-specific correction map is obtained with zero-differenced (ZD) carrier phase residuals in this method. However, when more precise double-differenced (DD) residuals are used, this method may be not suitable to transform DD residuals into ZD residuals due to the assumption [23]. Therefore, Dong et al. (2016) proposed a lookup table method for multipath reduction based on a multipath hemispherical map (MHM) and compared the technique with SF/advanced SF (ASF) [24]. In this method, the observation residual of the fixed single-difference (SD) ambiguity between the two antennas is averaged. The low frequency multipath effect is retained and can be modeled while the noise effect is weakened. Moreover, Zheng et al. (2019a) proposed a modified multipath hemispherical map model (M-MHM), which constructs grids from raw carrier-phase residuals [25]. The M-MHM exhibits the most improvement compared with the SF method and original MHM, but the model residuals using the PPP technique may include orbital, clock and atmosphere errors [26].

Most of the above studies are for GPS, for which the orbital repetition period is about one sidereal day. However, BDS-2 has three constellation satellites with different orbital repetition periods. Ye et al. (2015) analyzed the repeat period of different BDS-2 satellites and used sidereal filtering to mitigate BDS-2 carrier phase multipath errors [27]. The improvement of the positioning results is obvious. It is well known that the SF using single difference can mitigate GPS multipath effectively, Ye et al. (2015) recovered the $\mathrm{SD}$ residuals from DD residuals based on the assumption that the sum of observed SD 
residuals is zero [27]. However, the application of the simple "zero mean" assumption will introduce new errors to BDS-2 positioning. Therefore, the MHM proposed by Dong et al. (2016) solves the problem of "zero mean" assumption, but its effective distance is limited by the common receiving clock of two antennas [28]. In addition, most of the research was conducted through artificial simulation of multipath environment for model verification, which is different from the actual application environment, such as for dam deformation monitoring. The observation environment of dam deformation monitoring is relatively complex, with multipath interference of water surface and slope. Most of these studies have confirmed that the positioning accuracy and application of BDS-2 DD are comparable to that of GPS. However, there is little research on the multipath correction methods of BDS in the actual and complex environment.

For the complex actual environment and the multi-constellation characteristics of BDS-2, based on the multipath hemispherical map, we studied and assessed the multi-point hemispherical grid model (MHGM) and SF methods with actual BDS-2 dam monitoring data. Firstly, the new errors introduced by the simple "zero mean" assumption existing in the SF method do not need to be considered with this technique. The applicability of the MHGM is not affected by the different orbit repetition periods, so it is especially suitable for BDS-2. In addition, the use of DD residuals to model multipath error does not require specialized receiver equipment, and the distance between stations is not limited by hardware considerations. Finally, the actual BDS dam deformation monitoring data were used for verification and analysis. We compare MHGM with the SF method and focused on the multipath effects of carrier phase observations for actual and complex applications, such as dam deformation monitoring.

\section{Materials and Methods}

When the receiving antenna is located in a plane horizontal reflector and its transmission is only affected by a single reflected signal, the multipath error effect on the carrier phase can be expressed as follows [29]:

$$
\Delta=\frac{\lambda}{2 \pi} \tan ^{-1} \frac{\alpha \sin \left(4 \pi \frac{H}{\lambda} \sin \varepsilon\right)}{1+\alpha \cos \left(4 \pi \frac{H}{\lambda} \sin \varepsilon\right)}
$$

where $H$ is the antenna height; $\varepsilon$ and $\alpha$ are the incidence angle and the reflection coefficient of the reflected signal, respectively and $\lambda$ is the wavelength of the satellite signal.

The main steps of SD observation domain filtering include the following. Firstly, the BDS-2 data of the reference day are processed in static mode, and then the final baseline can be achieved after the ambiguities are resolved. Second, the integer ambiguities and baseline solution are brought back to the BDS-2 DD observation, and the DD residuals including the multipath error can be obtained. Based on the simple "zero mean" assumption, the SD residuals are recovered from DD residuals through a transfer matrix at each epoch [19]. Finally, the multipath model of BDS after smoothing the SD residuals can be established. However, since the orbital repetition period of the MEO and GEO/IGSO is different and the carrier phase multipath errors of GEO satellites are systematic, the application of the simple "zero mean" assumption introduces new errors to BDS-2 positioning. Therefore, learning from the multipath hemispherical map of Dong et al. (2016), the MHGM was proposed and developed.

\section{Multi-Point Hemispherical Grid Model (MHGM)}

For a certain wavelength of signal, the multipath error depends upon the reflection coefficient and the angle of incidence of the reflected signal, as well as the spatial relationship between the antenna and the reflector. If the antenna is fixed during the observation process, the spatial relationship between the antenna and the reflector always remains unchanged. However, the propagation path of the reflected signal varies with the direction of the satellite signal, and the incidence angle and reflection coefficient change accordingly 
to affect the multipath error. Since the multipath effect is related to the observation environment around the station, the observation environment changes as the time span of multipath modeling increases (weather, surrounding vegetation, etc.). Thus, using the observation data of nearby periods as much as possible for multipath modeling helps to reduce the impact caused by environmental changes.

According to the above characteristics of the multipath effect in the spatial domain, a hemisphere coordinate can be defined with the antenna's position as the center, and the position of a point can be described by a pair of angular coordinates (i.e., elevation and azimuth). Assuming that the environment around the station does not change with time, the multipath effect of the point in the hemispheric coordinate is only related to the elevation and azimuth of the satellite, but not to the observation time of the signal or the pseudorandom noise (PRN) code of the satellite. Based on the above assumptions, a novel multi-point hemispherical grid model was studied.

With the signal puncture point of all satellites, the observation data are used for overall modeling. It is not required that only the same satellite is modeled after the corresponding orbit repetition period $[19,23]$. This method can isolate multipath error using DD residuals between stations, and is consistent across stations. For each station, taking the elevation angle as the latitude and the azimuth angle as the longitude, a polar coordinate is constructed to describe the multipath error. The minimum latitude value of grid point is set to $\mathrm{B} 0$, and the maximum value is set to $\mathrm{B} 1$. According to the range of azimuth angle, the longitude of grid points is set from 0 to 360 degrees. The interval of the latitude and longitude components is $d_{b}$ and $d_{l}$, respectively, which determine the number of grid point parameters to be estimated in the model. The more grid points that are estimated, the more detailed the description of multipath error. In addition, for the same grid point parameter, when the satellite passes near the corresponding direction of the grid point, it can contribute to the modeling of the multipath error of the grid point. Therefore, the effectiveness of the modeling data can be improved.

An example of how the grid can be divided for a set of stations is given below $\left(B_{0}=0^{\circ}\right.$, $B_{1}=45^{\circ}, d_{b}=45^{\circ}, d_{l}=45^{\circ}$ ). For each set of fixed DD ambiguities $\Delta \nabla N$, the four zerodifferenced (ZD) observed minus calculated residuals in the corresponding period can be obtained, and then the DD residuals of carrier-phase observation can be calculated as:

$$
D D \text { residuals }=\left(Z D_{m}^{j}-Z D_{m}^{k}\right)-\left(Z D_{n}^{j}-Z D_{n}^{k}\right)-\lambda \cdot \Delta \nabla N
$$

where indexes $m$ and $n$ refer to the stations, and $j$ and $k$ refer to the satellites.

Figure 1 shows that the multipath error between the station $m$ and the satellite $j$ is assumed to involve the grid points. The number of grid points is determined by the satellite elevation angle. If the elevation angle of satellite is higher than $B_{1}$, there are three $\left(Q_{m 1}^{j}\right.$, $\left.Q_{m 2}^{j}, Q_{m 3}^{j}\right)$ points parameters, or four $\left(Q_{m 1}^{i}, Q_{m 2}^{i}, Q_{m 3}^{i}, Q_{m 4}^{i}\right)$ points parameters. When the grid point parameters are estimated using a sequential least square filter, the multipath error at $V_{m}^{i}$ in the grids can be calculated by bilinear interpolation.

$$
\begin{gathered}
V_{m}^{i}=\mathcal{W}_{m 1}^{j} \mathcal{Q}_{m 1}^{i}+\mathcal{W}_{m 2}^{j} \mathcal{Q}_{m 2}^{i}+\mathcal{W}_{m 3}^{j} \mathcal{Q}_{m 3}^{i}+\mathcal{W}_{m 4}^{j} \mathcal{Q}_{m 4}^{i} \\
\left\{\begin{array}{l}
\mathcal{W}_{m 1}^{j}=\frac{\left(b_{2}-b\right)\left(l_{2}-l\right)}{\left(b_{2}-b_{1}\right)\left(l_{2}-l_{1}\right)} \mathcal{W}_{m 2}^{j}=\frac{\left(b_{2}-b\right)\left(l-l_{1}\right)}{\left(b_{2}-b_{1}\right)\left(l_{2}-l_{1}\right)} \\
\mathcal{W}_{m 3}^{j}=\frac{\left(b-b_{1}\right)\left(l-l_{1}\right)}{\left(b_{2}-b_{1}\right)\left(l_{2}-l_{1}\right)} \mathcal{W}_{m 4}^{j}=\frac{\left(b-b_{1}\right)\left(l_{2}-l\right)}{\left(b_{2}-b_{1}\right)\left(l_{2}-l_{1}\right)}
\end{array}\right.
\end{gathered}
$$

where $(b, l)$ is the longitude and latitude of $V_{m}^{i}$. The longitude and latitude of the four grid point parameters $Q_{m 1}^{i}, Q_{m 2}^{i}, Q_{m 3}^{i}$ and $Q_{m 4}^{i}$ are $\left(b_{1}, l_{1}\right),\left(b_{1}, l_{2}\right),\left(b_{2}, l_{2}\right)$ and $\left(b_{2}, l_{1}\right)$, respectively. 
When the number of grid points is three $\left(Q_{m 1}^{j}, Q_{m 2}^{j}, Q_{m 3}^{j}\right)$, the multipath error at $V_{m}^{j}$ can be written as

$$
\left\{\begin{aligned}
V & =(1-u-v) \mathcal{Q}_{m 1}^{i}+u \mathcal{Q}_{m 2}^{i}+v \mathcal{Q}_{m 3}^{i} \\
u & =\frac{\left(b_{2}-b_{1}\right)\left(l-l_{1}\right)-\left(b-b_{1}\right)\left(l_{3}-l_{1}\right)}{\left(b_{2}-b_{1}\right)\left(l_{2}-l_{3}\right)} \\
v & =\frac{\left(b-b_{1}\right)\left(l_{2}-l_{1}\right)-\left(b_{2}-b_{1}\right)\left(l-l_{1}\right)}{\left(b_{2}-b_{1}\right)\left(l_{2}-l_{3}\right)}
\end{aligned}\right.
$$
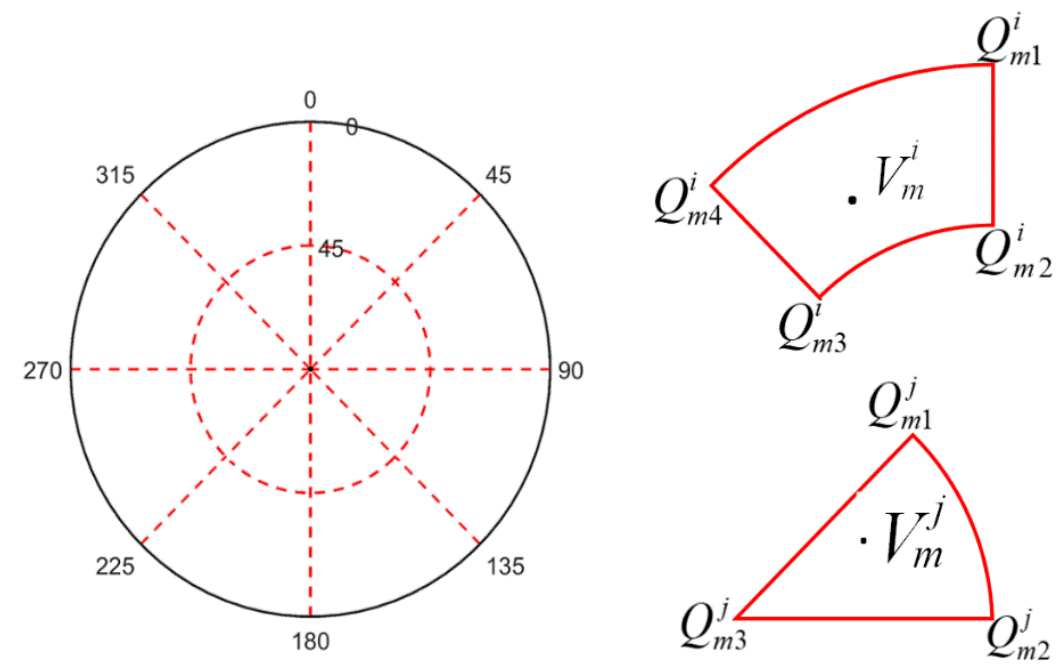

Figure 1. Distribution of hemispherical grid points.

Similarly, the values of $V_{m}^{k}, V_{n}^{j}$ and $V_{n}^{k}$ parameters between stations and satellites can also be determined. The DD residuals also can be expressed as follow:

$$
D D \text { residuals }=\left(V_{m}^{j}-V_{m}^{k}\right)-\left(V_{n}^{j}-V_{n}^{k}\right)-\lambda \cdot \Delta \nabla N
$$

The normal equation corresponding to the parameters of relevant grid points is constructed by using Equation (6), and the solution of different satellites, stations and time periods can be realized by the superposition of the normal equation. Any constellation of the BDS-2 satellites can obtain the multipath correction according to the satellite altitude and azimuth.

\section{Results}

Position and Navigation Data Analyst (PANDA) software originally developed by Wuhan University was modified to obtain DD residuals between satellites and stations [30]. Firstly, the ZD residuals between station and satellites were attained directly by PANDA using the ZD processing mode [31]. Then, the ZD ambiguities were mapped to a maximum set of independent DD ambiguities, and the DD ambiguities could be solved and fixed sequentially.

\subsection{Data Collection and Processing}

In order to assess the performance of the MHGM, BDS-2 data collected as a part of the deformation monitoring of reservoir were processed. The SF method was used as a comparison to prove the advantage of MHGM. As shown in Figure 2, four BDS-2 stations were built on the dam and all the stations were capable of capturing BDS signal with $1 \mathrm{~Hz}$ sampling rate. The date spans a period of time from DOY 44 to 55 of the year 2019. The satellite orbital repeat times for BDS-2 satellites were computed using Keplerian orbital elements from broadcast ephemerides. Generally, the orbital repeat times are $86155 \mathrm{~s}(23 \mathrm{~h}$ $55 \mathrm{~min} 55 \mathrm{~s}$ ) for BDS-2 GEO/IGSO and six days plus $84697 \mathrm{~s}$ ( $23 \mathrm{~h} 31 \mathrm{~min} 37 \mathrm{~s}$ ) for BDS-2 
MEO. Details of the models and strategies related to data processing of PANDA software are shown in Table 1.
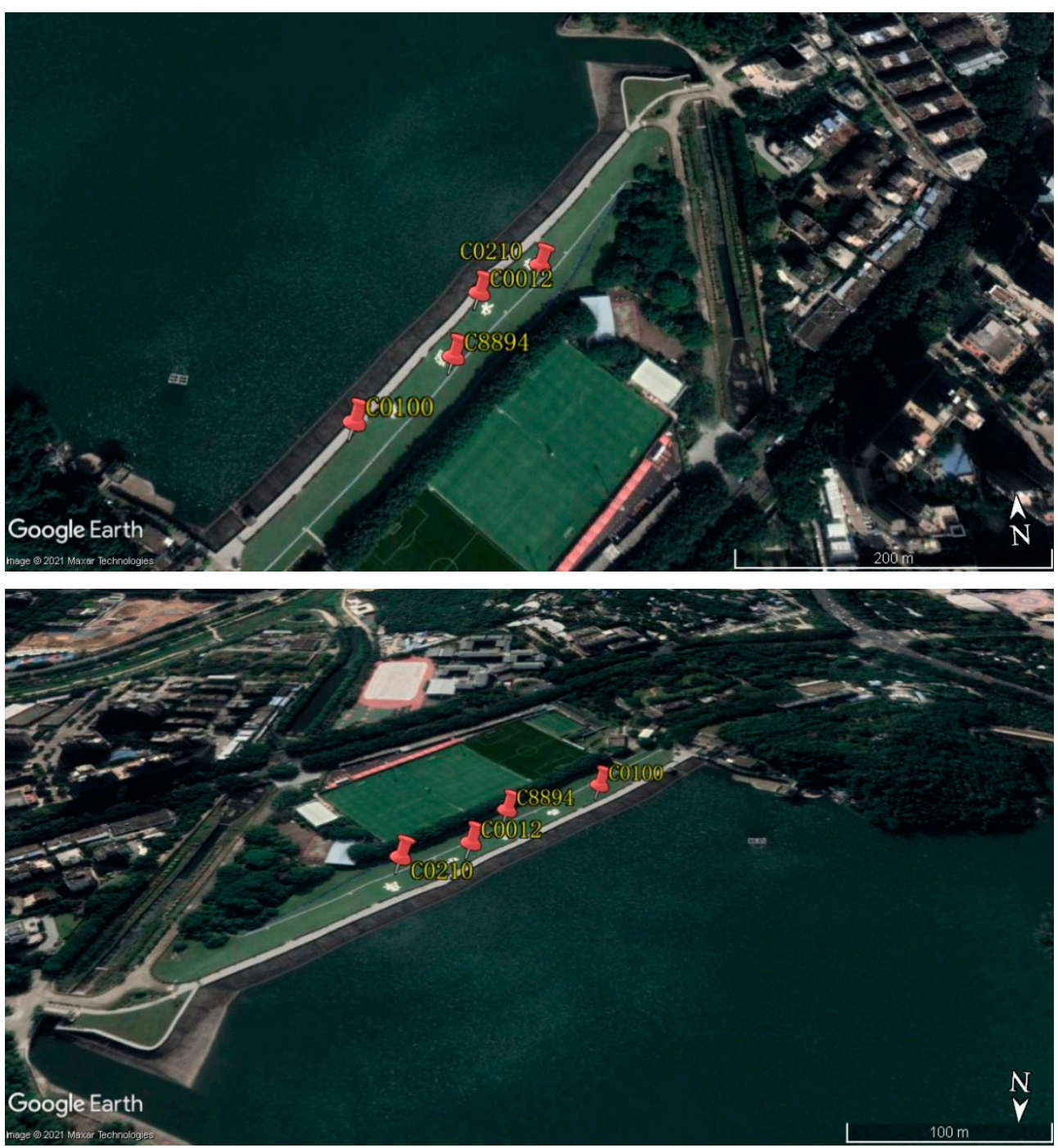

Figure 2. Distribution of BDS-2 stations used for reservoir deformation monitoring, where the C0100 station is the base station and the other stations are monitoring stations (the origin of the background image is Google Earth).

Table 1. Model and parameters for data processing.

\begin{tabular}{ccc}
\hline Parameter & Model & Constraint \\
\hline Observation & BDS-2 B1 & 0.02 cycle, $1.0 \mathrm{~m}$ \\
Observation weight & Satellite elevation & $/$ \\
Cutoff elevation & 7 degree & $/$ \\
Phase center pattern & igs14.atx & priori covariance \\
Tropospheric delay & Saastamoinen + GMF & $0.001 \mathrm{~m}$ \\
Satellite clock & Broadcast & $/$ \\
Receiver clock & Range estimating & priori covariance $9000 \mathrm{~m}$ \\
EOP & + White noise & $/$ \\
\hline
\end{tabular}

The model parameters were set as follows: $B_{0}=5^{\circ}, B_{1}=85^{\circ}, d_{b}=2^{\circ}$ and $d_{l}=2^{\circ}$. In order to improve the reliability of the MHGM results, three equations are involved in the 
solution. In addition, correlation constraints were added between grid point parameters, and the absolute value of grid point parameters was less than $1 / 4$ wavelength [3]. In order to reduce the coarse value and improve the stability of grid point results, the additional correlation constraint between the grid point parameters was imposed. It was found that setting the value from $5 \mathrm{~mm} /$ degree to $5 \mathrm{~cm}$ /degree has little effect on the final model result, so the empirical variation value was set to $1.0 \mathrm{~cm} /$ degree.

For both MHGM and SF methods, the same fixed DD ambiguities were used to establish the multipath model. The DD residuals before the day of interest were shifted according to the orbital repeat time and then stacked for each pair. These stacked residuals were low-pass filtered with a cutoff of $10 \mathrm{~s}$ to generate multipath corrections. Finally, the phase observations on the day of interest were corrected, and then processed for kinematic relative positioning in simulated real time. The strategies of the solution adopted in this study are as shown in Table 2. For example, if the date of the test data is DOY 51, the modeling data of GEO/IGSO and MEO for the SF method are DOY 50 and 44, respectively. The modeling data of GEO/IGSO and MEO for the MHGM method were from DOY 44 to 50 , which is a total of seven days and so on for other test data days.

Table 2. Solution strategies for multipath error analysis (DOY in 2019).

\begin{tabular}{cccc}
\hline \multirow{2}{*}{ Strategy } & \multicolumn{2}{c}{ Modeling Data } & \multirow{2}{*}{ Test Data } \\
\cline { 2 - 3 } & GEO/IGSO & MEO & $51-55$ \\
NO & $/$ & $/$ & $51-55$ \\
SF & $50-54$ & $44-48$ & $51-55$ \\
MHGM & $44-54$ & $44-54$ & 54 \\
\hline
\end{tabular}

\subsection{MHGM for Deformation Monitoring}

Corresponding to the strategies shown in Table 2, Figures 3 and 4 show the results of the MHGM using DOY 44-50 observation data at all the stations, and the hemispherical modeling results of DOY 50 and 53 are shown as examples. The horizontal and vertical axes represent the azimuth angle and elevation angle, respectively.

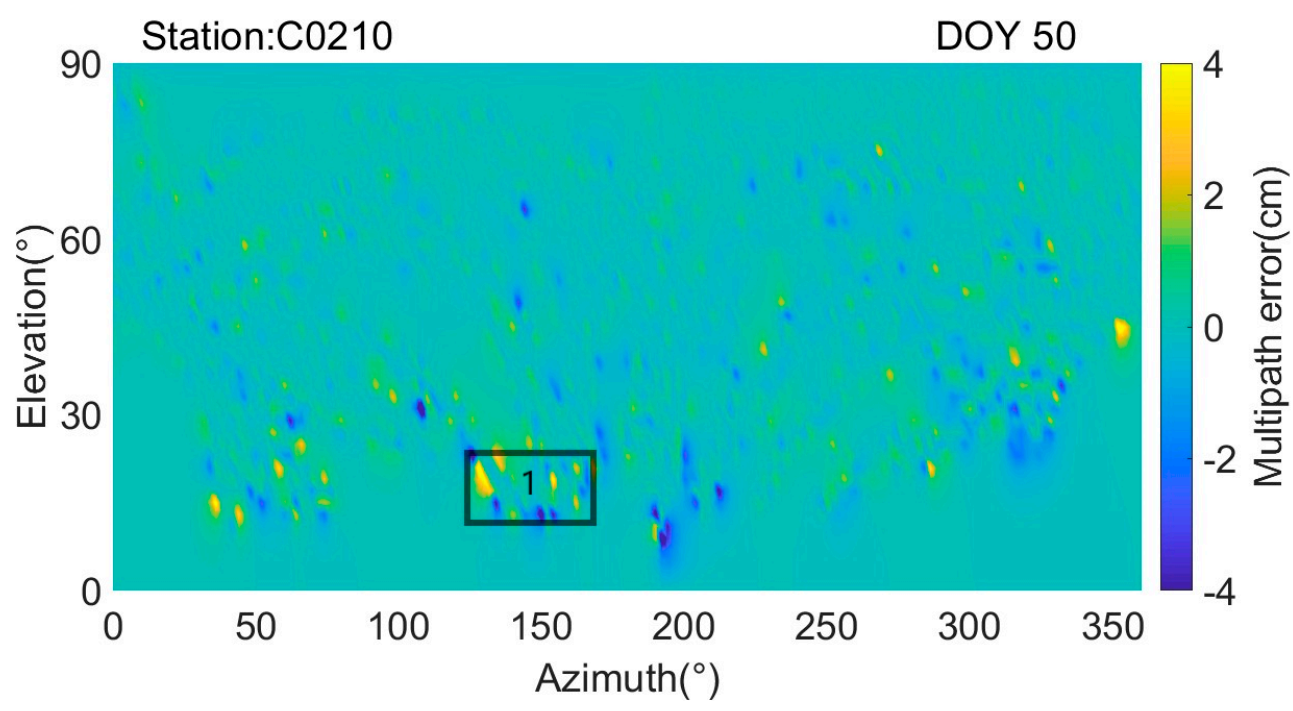

Figure 3. Cont. 

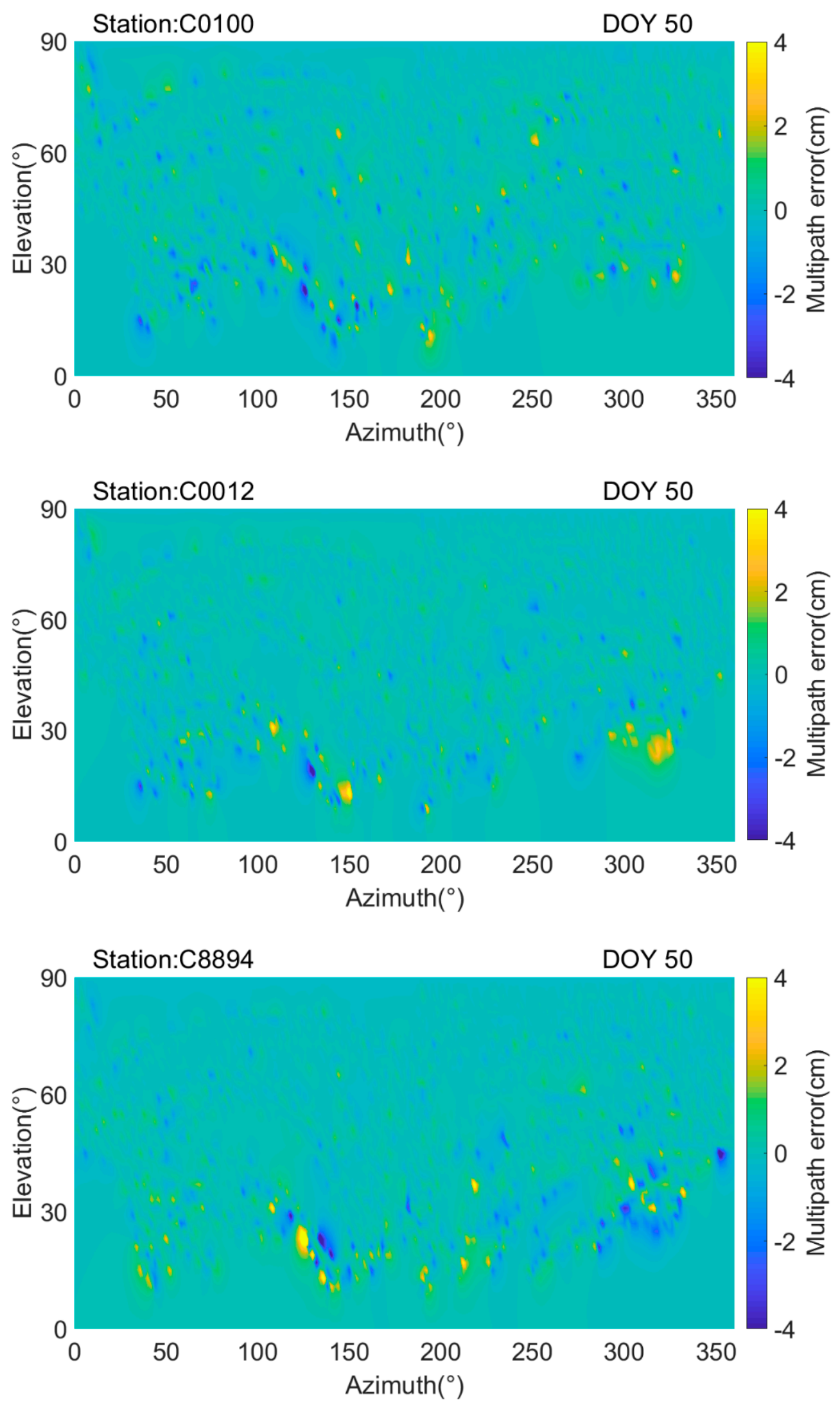

Figure 3. MHGM modeling results for DOY 50 at the C0210, C0100, C0012 and C8894 stations. The horizontal and vertical axes represent the azimuth and elevation angle, respectively. Different colors indicate different multipath error values. 

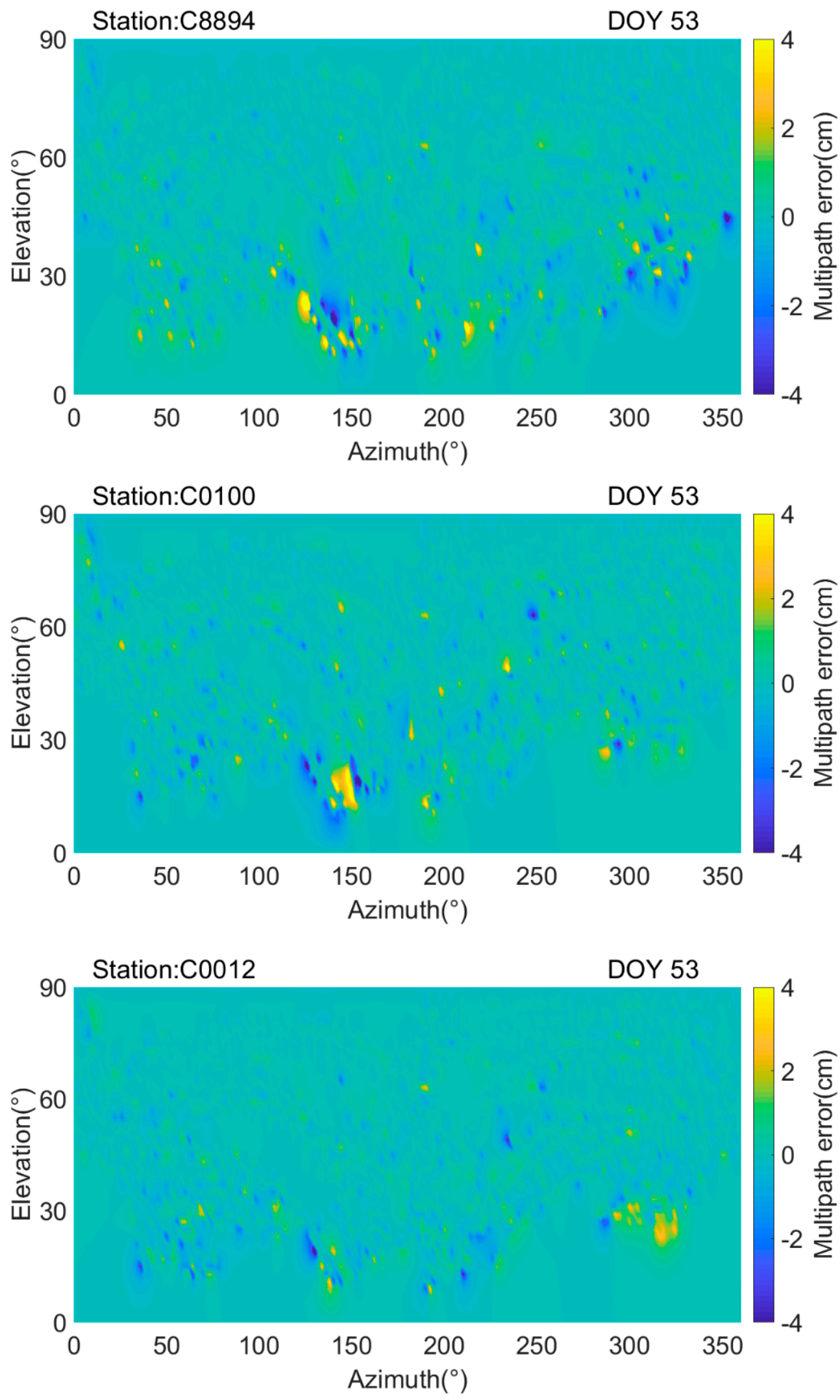

Figure 4. Cont. 


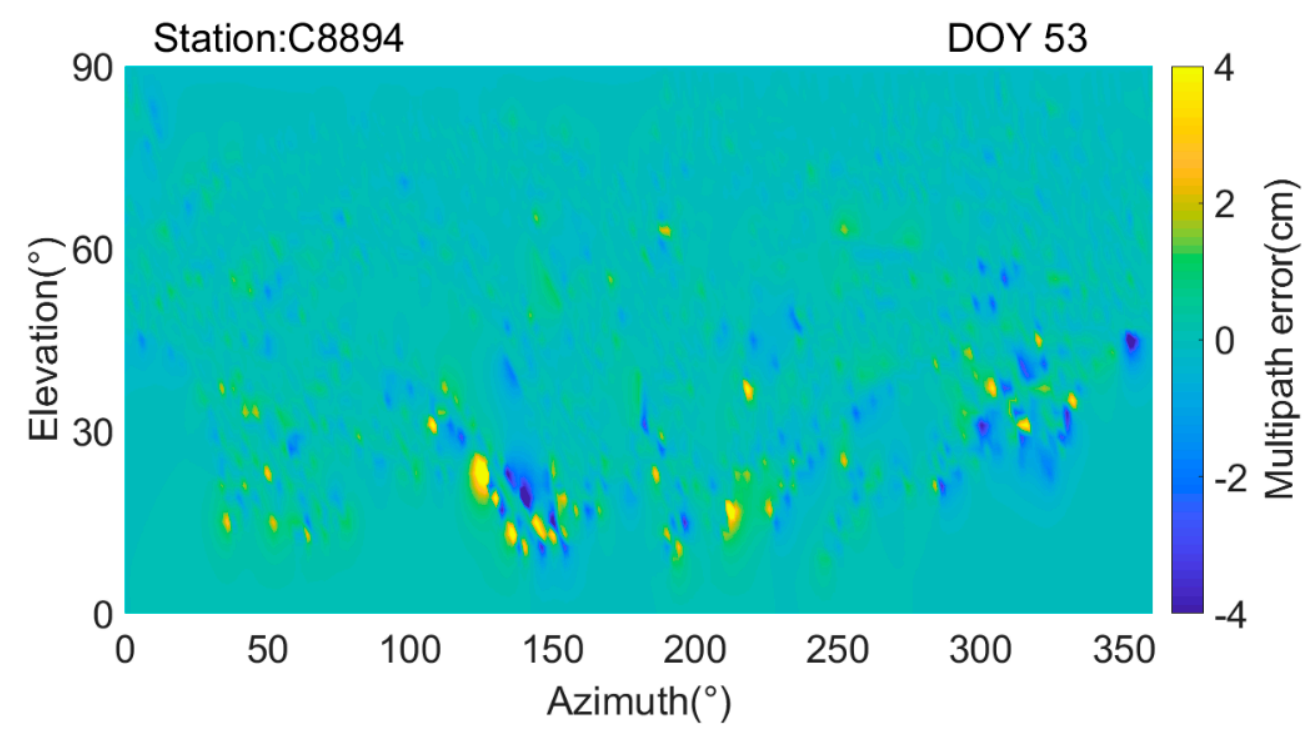

Figure 4. MHGM modeling results for DOY 53 at the C0210, C0100, C0012 and C8894 stations. The horizontal and vertical axes represent the azimuth and elevation angle, respectively. Different colors indicate different multipath error values.

Since the observation environment of all stations is similar, the hemispherical modeling results in Figures 3 and 4 of all stations are similar. It can be found in Figures 3 and 4 that the maximum value of multipath error can be up to $4 \mathrm{~cm}$. The most serious areas of multipath error in Figures 3 and 4 for different day are approximately symmetrical, which indicate that it is caused by static objects. In the dam observation environment, larger multipath error are usually caused by the water surface reflection and the mountain slope. As shown in rectangle 1 of Figure 3, the maximum value of multipath error appears between $120^{\circ}$ and $150^{\circ}$ in DOY 50, and it can be noticed from Figure 2 that this direction is facing the mountain slope. The same result also appears in Figure 4 for DOY 53. The azimuth direction of between $300^{\circ}$ and $330^{\circ}$ is affected by water reflection. Even if the elevation angle is greater than $50^{\circ}$, the multipath error can still reach the maximum value in some directions. During the dam monitoring period, the surrounding environment is stable. Multipath distribution map is consistent with the surrounding environment, and the MHGM can reflect the observation environment of the station. This model can therefore be used to evaluate the possible multipath error sources around the station, and give some guidance to eliminate the influence of multipath error sources in the physical sense. In additoin, it does not require any hardware modification and could be easily applied to different kinds of hardware and software systems of a deformation monitoring environment.

\subsection{DD Residual Analysis}

After the multipath values of the grid points are obtained, the multipath correction of any point can be interpolated. The multipath error was corrected for the observations, which were processed in real-time kinematic relative positioning mode. As shown in Table 2, the SF model has to be estimated based on the different orbital repeat times of GEO/IGSO and MEO. Since the total time of the observation is about 12 days, the SF model uses 1 day-old data for GEO/IGSO and 7 day-old data for MEO. However, MHGM can make full use of the observation data, and all the 7 day-ago data during the experiment could be used for estimating MHGMs.

Due to using the multipath errors of different periods to correct the observations in the SF method, the corresponding observations of GEO/IGSO and MEO satellites introduce different references of the multipath errors. Thus, the DD between GEO/IGSO and MEO also introduces new error. In order to ensure and improve the modeling accuracy, only the observation data of the repeat periods are used to model in the SF method, so the multipath error of following repeat periods cannot be mitigated if the corresponding period ambiguity 
of the previous day is not effectively fixed. Moreover, the MHGM can use the data observed during different periods and multi-day historical data to improve the consistency and availability of the modeling.

In order to assess the efficiency of the MHGM and the error caused by orbital repeat time of the SF method, the DD residuals between GEO/IGSO and MEO were analyzed separately. Therefore, there are three kinds of DD residuals according to the orbital repeat times, namely GEO/IGSO, GEO/IGSO+MEO and MEO. Since the observation conditions of the four stations are the same, the sky plots and observed BDS-2 satellites at only C0100 station given in Figure 5. Figure 6 show the DD residuals of the different strategies between different satellites for C04-C08, C09-C12 and C11-C14 at the stations C0012 and C0100 during the period of fixed ambiguity. Table 3 shows the mean RMS of three DD residuals for the three modes.

It can be found from Figure 5 that the observation time for GEO and IGSO is relatively longer. Compared with the DD combinations of GEO/IGSO+MEO and MEO, the DD residuals of GEO/IGSO are the largest. As shown in Figure 6, the residuals of the MHGM method are the smallest. Moreover, it can be seen from Table 3 that the RMS of DD residuals with the multipath correction does not exceed $7 \mathrm{~mm}$. Compared with the result without considering multipath correction, the RMS values of GEO/IGSO, GEO/IGSO+MEO and MEO for SF were improved by about $9.1 \%, 7.5 \%$ and $8.7 \%$, respectively. The DD residuals of the GEO/IGSO and MEO for the MHGM method are slightly better than those of the SF method, and the improvement with respect to the SF method is $4.5 \%$ and $6.5 \%$, respectively. Moreover, the improvement of GEO/IGSO+MEO by the MHGM can be up to $17.0 \%$, since MHGM avoids different references of the multipath errors and solves the problem of "zero mean" assumption in the SF method. The performance of GEO/IGSO+MEO for MHGM method is the same as that of MEO, which is not affected by the different orbital repeat times of BDS-2 satellites, which further proves that MHGM is more effective than the SF method in some cases.

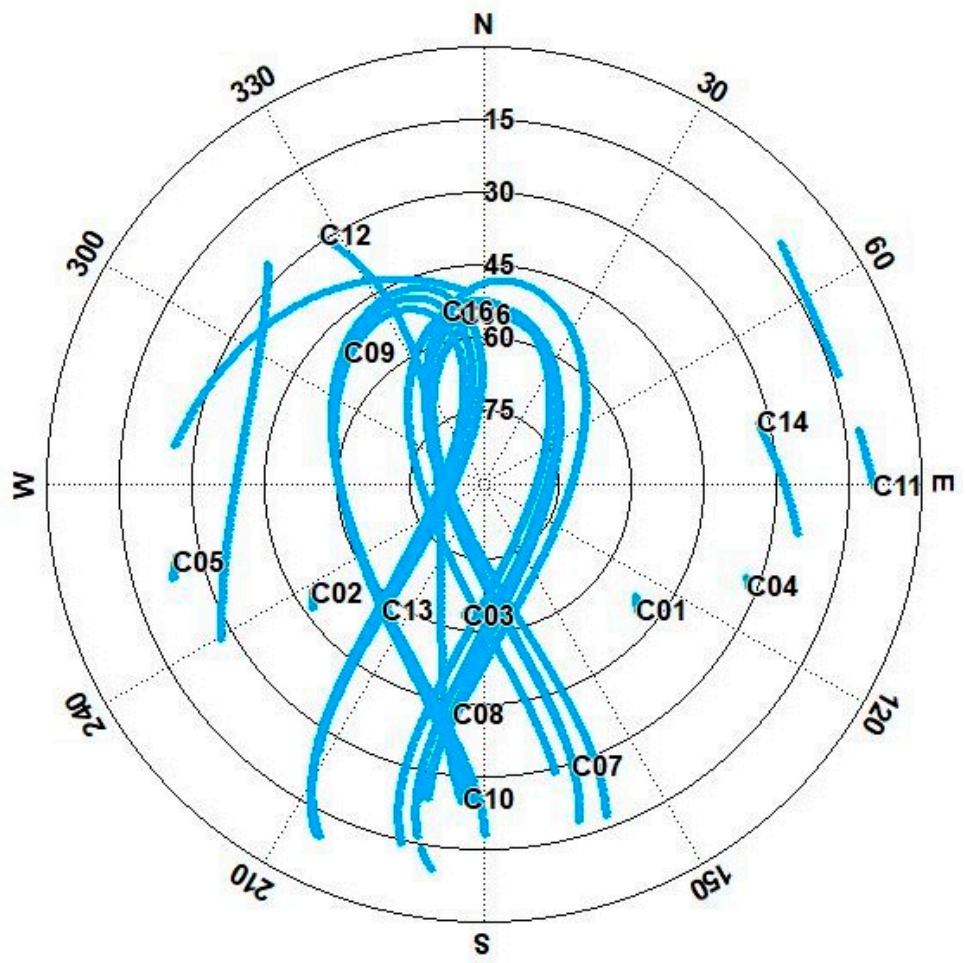

(a)

Figure 5. Cont. 


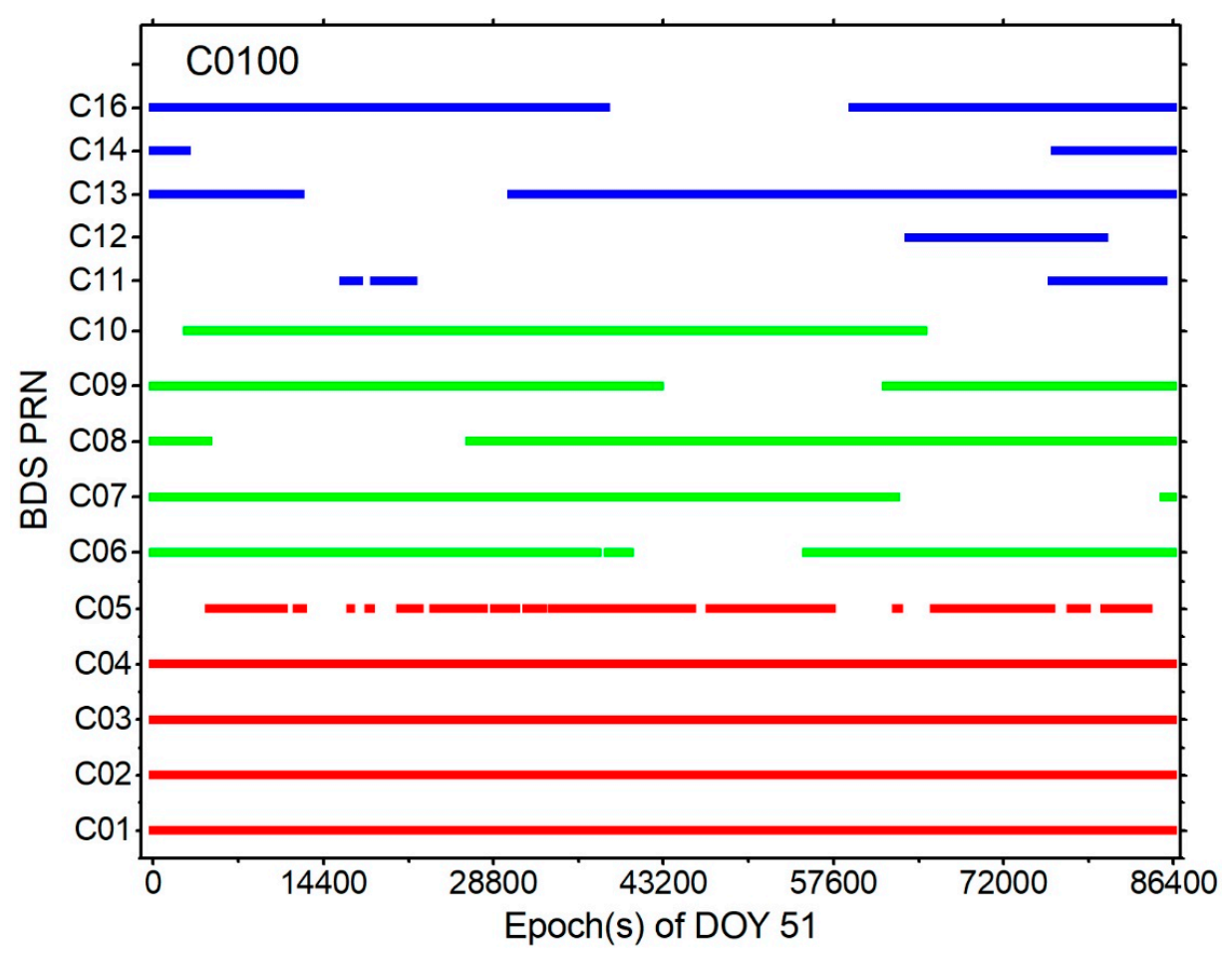

(b)

Figure 5. Sky plots (a) and observed BDS-2 satellites (b) at C0100 station (It should be noted that C13 and $\mathrm{C} 16$ belong to IGSO during the observation period in this study).

\subsection{Positioning Performance of SF and MHGM Methods}

In order to assess the performance of multipath error correction using the SF and MHGM methods in the positioning domain, relative positioning was carried out. Station C0012 was set as the base station and fixed in the data processing, and the position of static stations C0100, C0210 and C8894 were estimated according to Tables 1 and 2 in real-time static and kinematic relative positioning mode. In the static mode, the data were processed with a $2 \mathrm{~h}$ interval. Taking the DOY 51 test as an example, the positioning errors of static and kinematic relative positioning for station C0100, C0210 and C8894 are displayed in Figure 7. Moreover, the mean RMS of position errors for DOY from 51 to 55 is presented in Table 4 among all the three stations solutions.

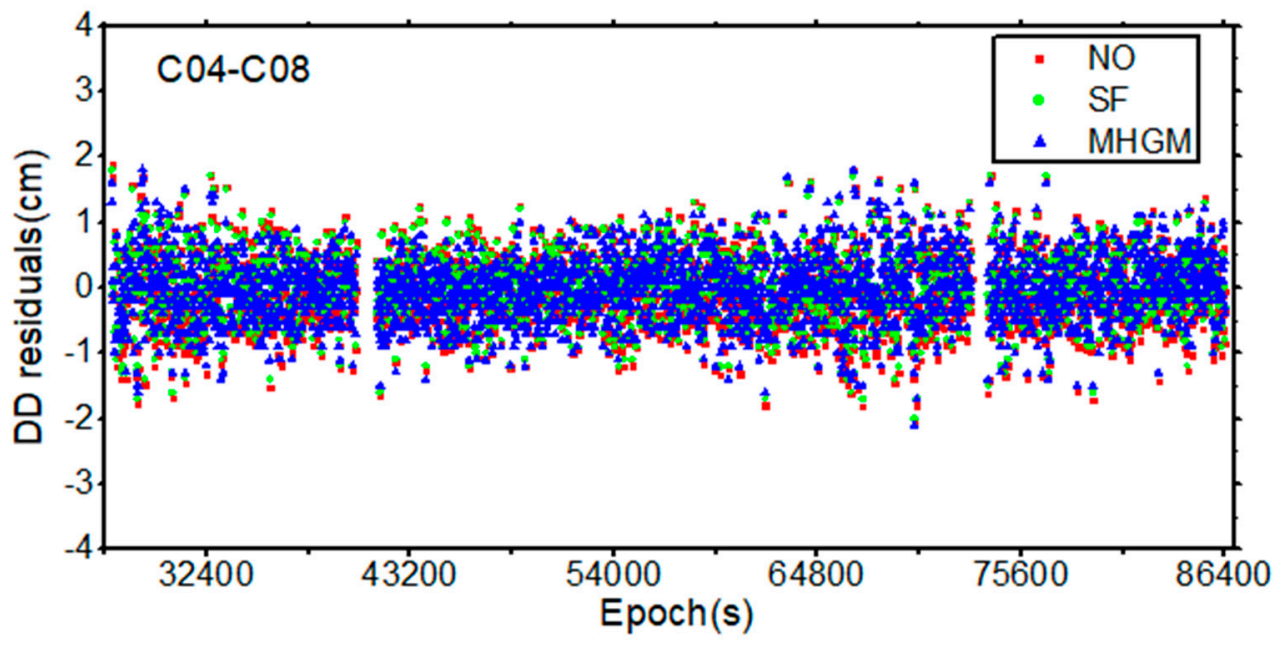

Figure 6. Cont. 

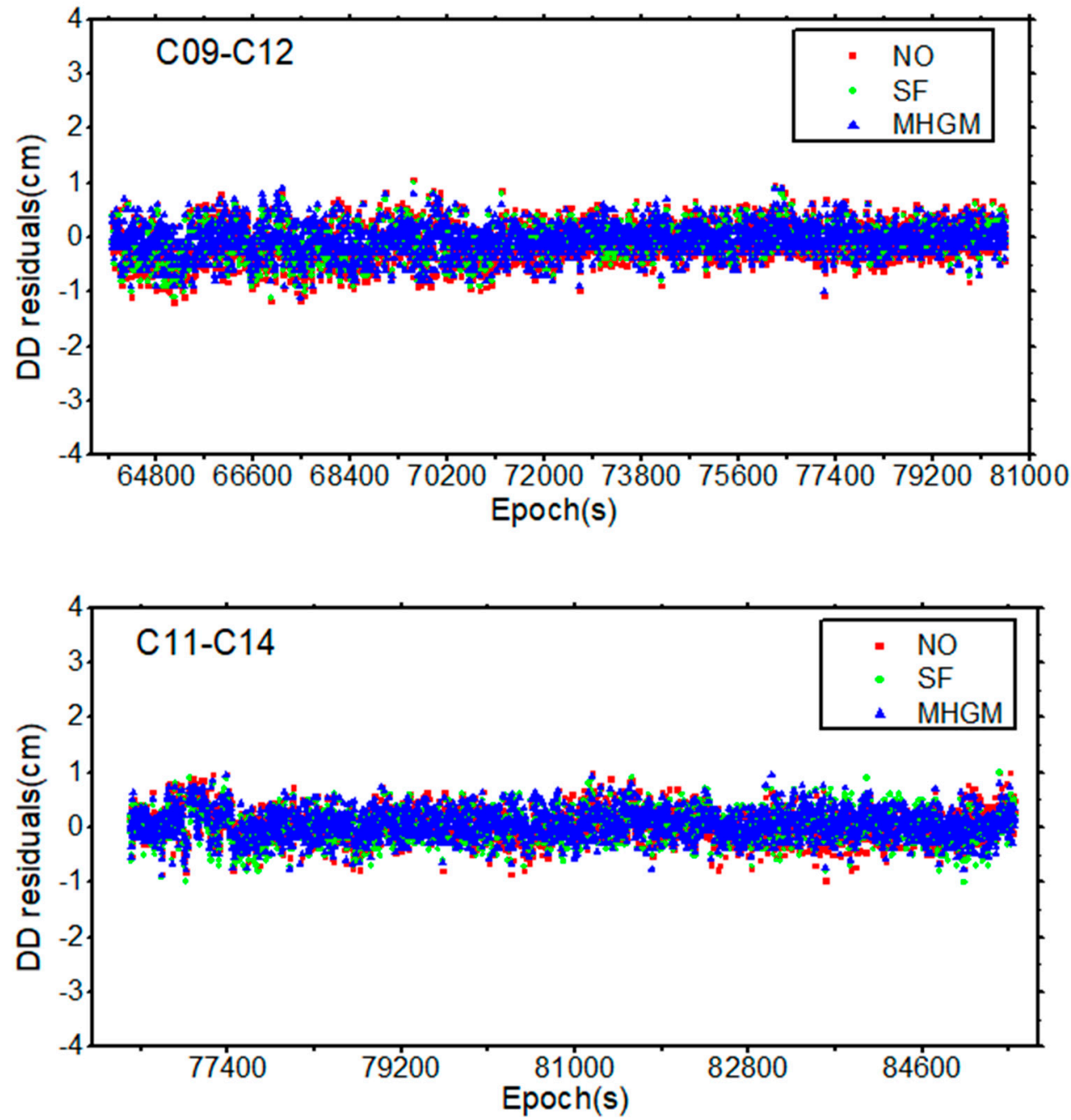

Figure 6. DD residuals of C04-C08 (DD between GEO and ISGO), C09-C12 (DD between ISGO and MEO) and C11-C14 (DD between MEO and MEO) between the stations 0012 and 0100, NO indicates that no multipath error correction has been made, SF represents the sidereal filtering model and MHGM represents the multi-point hemispherical grid model.

Table 3. DD residuals of three different models, GEO/IGSO represents the DD between GEO and ISGO satellites, GEO/IGSO+MEO represents the DD between GEO/IGSO and MEO satellites and MEO represents the DD between MEO and MEO satellites.

\begin{tabular}{cccc}
\hline \multirow{2}{*}{$\begin{array}{c}\text { Satellites for DD } \\
\text { Combinations }\end{array}$} & GEO/IGSO & GEO/IGSO+ MEO & MEO \\
\cline { 2 - 4 } & 6.6 & 5.3 & 4.6 \\
NO & 6.0 & 4.9 & 4.2 \\
SF & 5.7 & 4.0 & 3.9 \\
\hline
\end{tabular}




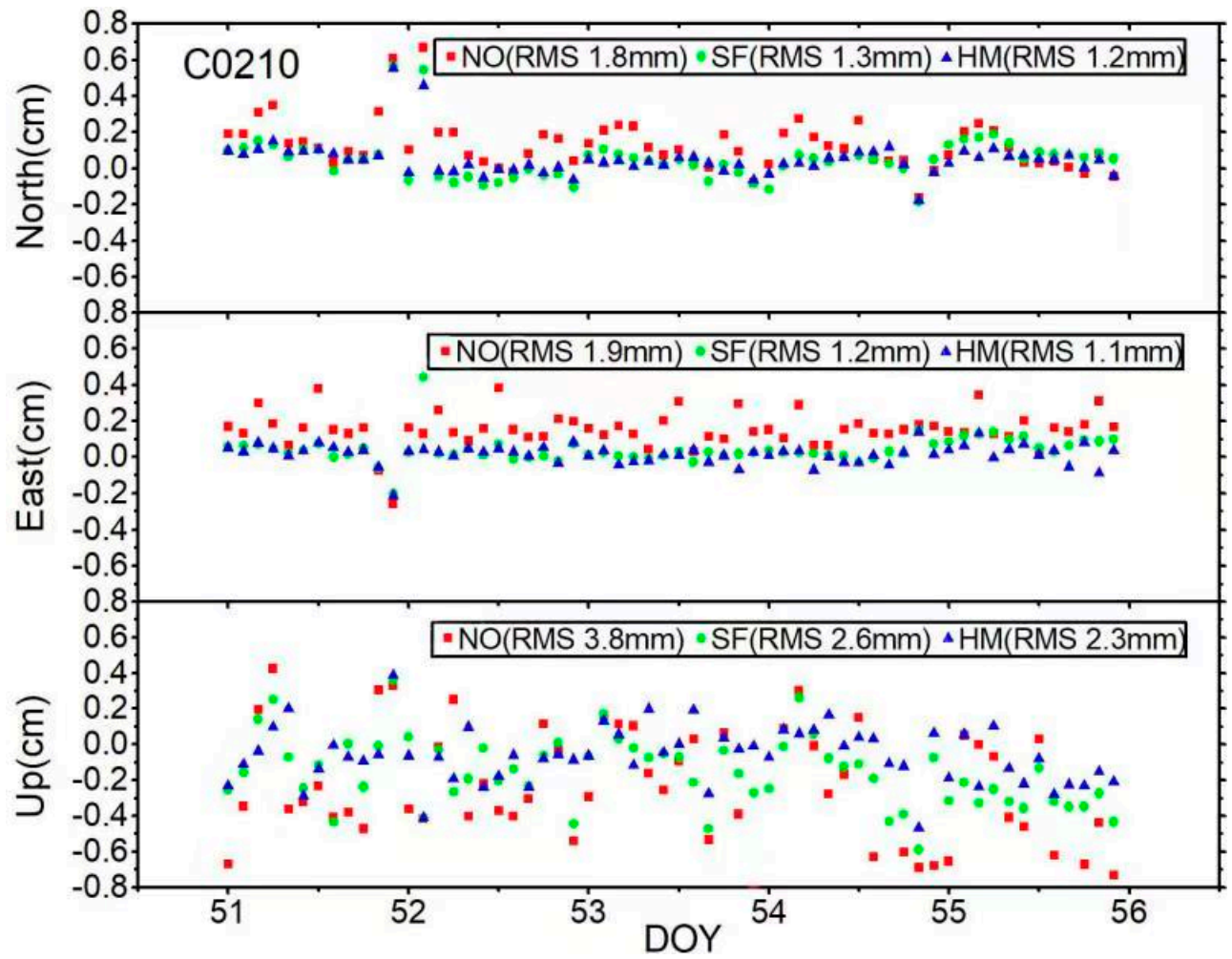

(a)

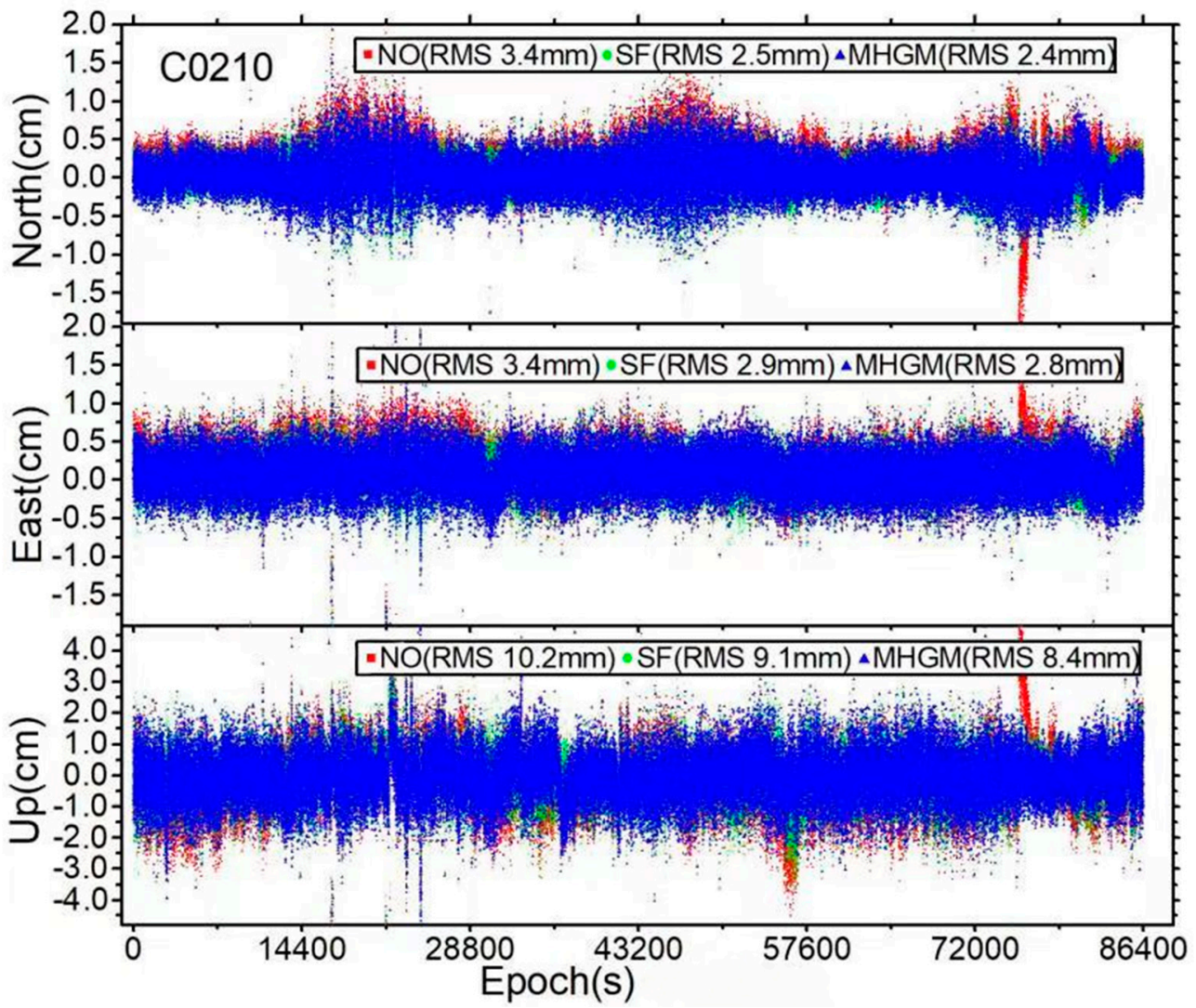

(b)

Figure 7. Static with a $2 \mathrm{~h}$ interval (a) and kinematic positioning error sequence (b) of station 0210 (static with a $2 \mathrm{~h}$ interval result is from DOY 51 to 55 , kinematic result is form DOY 51). 
Table 4. Mean RMS of static with a $2 \mathrm{~h}$ interval and kinematic positioning results from DOY 51 to 55.

\begin{tabular}{ccccc}
\hline \multirow{2}{*}{ Strategy } & \multicolumn{2}{c}{ Static } & \multicolumn{2}{c}{ Kinematic } \\
\cline { 2 - 5 } & Horizontal $(\mathbf{m m})$ & Vertical $(\mathbf{m m})$ & Horizontal $(\mathbf{m m})$ & Vertical $(\mathbf{m m})$ \\
\hline NO & 2.3 & 3.7 & 4.3 & 9.4 \\
SF & 1.8 & 2.6 & 3.8 & 8.6 \\
MHGM & 1.7 & 2.4 & 3.6 & 8.1 \\
\hline
\end{tabular}

It can be seen from Figure 7 that the error in the north direction is periodic in kinematic mode, which may be caused by the influence of reservoir flow. This phenomenon and the specific reasons need further study. When the multipath error is uncorrected, the horizontal and vertical positioning errors of stations in static with a $2 \mathrm{~h}$ interval and kinematic mode are $2.3,4.3$ and $3.7,9.4 \mathrm{~mm}$, respectively. After using SF method to mitigate multipath error, the static and kinematic positioning errors of stations were improved, reaching 1.8, 3.8 and $2.6,8.6 \mathrm{~mm}$ in the horizontal and vertical direction, respectively, and the improvement was as high as $21.7 \%, 12.1 \%$ and $29.7 \%, 9.0 \%$. Moreover, the MHGM improved by $5.4 \%, 5.3 \%$ in the vertical direction compared with the SF method, and the improvement rate in static with a $2 \mathrm{~h}$ interval and kinematic mode was $4.3 \%, 4.6 \%$ in the horizontal direction, respectively. Moreover, for static with a $2 \mathrm{~h}$ interval and kinematic mode, the MHGM method improved about $26.1 \%, 16.3 \%$ and $35.1 \%, 13.8 \%$ with respect to the without multipath correction in the horizontal and vertical direction. It can therefore be found that the SF method is not as effective as the MHGM method in the presence of accurate BDS deformation monitoring environment.

\section{Discussion}

In this study, the multipath error was analyzed by using the actual data of dam deformation monitoring. Through the comparison with the SF method, some meaningful conclusions were obtained. Although the improvement effect in kinematic mode is not very obvious in this study $(>30 \%)$, we hope to provide a research reference for multi-constellation analysis with different periods of BDS-2 and a practical engineering application. However, the multipath error caused by the reflection of the water surface was not considered in this study. The next step is to consider the reflection of the water surface or adding a water surface reflection suppression plate. Furthermore, the observation data is 12 days in total. In addition to MHGM modeling, the actual data processed for verification were only DOY 51-55, which is insufficient for actual dam deformation monitoring.

Compared with the SF method, the MHGM can not only improve the effectiveness of multipath error, but also effectively provide a graphical display of multipath error interference around the stations. Because there are fewer MEO satellites and fewer doubledifference observations between GEO/IGSO and MEO in BDS-2, the improvement of the DD residuals and relative positioning is not very obvious. The MHGM avoids the multipath reference problem caused by different orbital repetition periods, which makes it more suitable for the combined multipath modeling of BDS-2 and BDS-3. It also has distinct potential for improving the data processing accuracy of IGS stations, and further improving the accuracy of IGS products in the future.

\section{Conclusions}

In this study, we analyzed and assessed the MHGM method for the mitigation of multipath error at stations based on a multi-point hemispherical grid model. The hemisphere centered on each station was divided into a grid, and the multipath error at the station was estimated with the parameterization of grid points. In the process of grid point parameter estimation, DD residuals corresponding to the fixed ambiguity solution of different satellite pairs and different time periods were used as the input information to obtain the MHGM of each station. The performance of the MHGM derived from the BDS-2 deformation monitoring of reservoir was analyzed and assessed, and the effectiveness of 
the MHGM with respect to the SF model was investigated. The feasibility and effect of BDS-2 data applied in dam deformation monitoring were also analyzed.

The results show that the MHGM can truly reflect the multipath error distribution of the reservoir dam, especially large multipath error caused by water surface reflection. This characteristic of the MHGM can be used to orientate the sources of multipath error around the station, and provides guidance to physically eliminating the influence of error sources. Based on the previous day's data modeling multipath error, the correction effect of the MHGM is better than that of the SF method. Multi-day of observation data can make the description of the MHGM more detailed. Compared with the SF method, the RMS of DD residuals was improved to a certain extent in the MHGM method, especially in the GEO/IGSO+MEO mode, where the improvement was as high as $17.0 \%$. The performances of the MHGM method are consistent and not affected by the different orbital repeat times, which solves the "zero mean" assumption problem of the SF method. The MHGM method has a more obvious effect in the positioning accuracy for static with a $2 \mathrm{~h}$ interval and kinematic mode, which can improve by about $26.1 \%, 16.3 \%$ and $35.1 \%, 13.8 \%$ with respect to the method without multipath correction in the horizontal and vertical direction.

Author Contributions: Conceptualization, X.Z. and Y.L.; methodology, X.Z.; software, X.Z.; validation, Z.L., Y.W. and C.D.; formal analysis, C.D.; investigation, Z.L.; writing-original draft preparation, X.Z.; writing-review and editing, X.Z. and Y.L.; visualization, J.C. and R.F.; supervision, W.T.; project administration, W.T.; funding acquisition, X.Z., W.T. and C.D. All authors have read and agreed to the published version of the manuscript.

Funding: This research was funded by the National Key Research and Development Program of China, grant number 2017YFB0503702; the National Natural Science Foundation of China, grant number 41804028 and 41874037; the Wuhan science and technology project, grant number 2018010401011271, and the Joint fund of Ministry of Education of China for Equipment Pre-research, grant number 6141A02022372.

Data Availability Statement: The data presented in this study are available on request from the author.

Acknowledgments: The authors would like to acknowledge the IGS for providing the broadcast ephemeris and precise products.

Conflicts of Interest: The authors declare no conflict of interest.

\section{References}

1. Braasch, M.S. Multipath effects. In Global Positioning System: Theory and Applications, Volume 1; Spilker, J.J., Jr., Axelrad, P., Parkinson, B.W., Enge, P., Eds.; AIAA Press: Washington, DC, USA, 1996.

2. Larson, K.; Bilich, A.; Axelrad, P. Improving the precision of high-rate GPS. J. Geophys. Res. 2007, 112, B05422. [CrossRef]

3. Hofmann-Wellenhof, B.; Lichtenegger, H.; Wasle, E. GNSS Global Navigation Satellite Systems: GPS, GLONASS, Galileo and More; Springer: Berlin/Heidelberg, Germany, 2008.

4. Van Nee, R.D.J. The multipath estimating delay lock loop. In Proceedings of the IEEE 2nd International Symposium on Spread Spectrum Techniques and Applications, Yokohama, Japan, 29 November-2 December 1992; pp. $39-42$.

5. Comp, C.J.; Axelrad, P. Adaptive SNR-based carrier phase multipath mitigation technique. Trans. Aerosp. Electron. Syst. 1998, 34, 264-276. [CrossRef]

6. Wen, H.; Pan, S.; Gao, W.; Zhao, Q.; Wang, Y. Real-time single-frequency GPS/BDS code multipath mitigation method based on C/N0 normalization. Measurement 2020, 164, 108075. [CrossRef]

7. Han, S.; Rizos, C. Multipath effects on GPS in mine environments. In Proceedings of the 10th International Congress of the International Society for Mine Surveying, Fremantle, Australia, 2-6 November 1997; pp. 447-457.

8. Souza, E.M.; Monico, J.F.G. Wavelet shrinkage: High frequency multipath reduction from GPS relative positioning. GPS Solut. 2004, 8, 152-159. [CrossRef]

9. Satirapod, C.; Rizos, C. Multipath mitigation by wavelet analysis for GPS base station applications. Surv. Rev. 2005, 38, 2-10. [CrossRef]

10. Zheng, D.; Zhong, P.; Ding, X.; Chen, W. Filtering GPS time-series using a Vondrak filter and cross-validation. J. Geod. 2005, 79, 363-369. [CrossRef]

11. Ge, L.; Han, S.; Rizos, C. Multipath mitigation of continuous GPS measurements using an Adaptive Filter. GPS Solut. 2000, 4, 19-30. [CrossRef] 
12. Yu, S.; Guo, F.; Zhang, X.; Liu, W.; Li, X.; Wu, R. A New Method for GNSS Multipath Mitigation with an Adaptive Frequency Domain Filter. Sensors 2018, 18, 2514. [CrossRef] [PubMed]

13. Suzuki, T.; Matsuo, K.; Amano, Y. Rotating GNSS Antennas: Simultaneous LOS and NLOS Multipath Mitigation. GPS Solut. 2020, 24, 86. [CrossRef]

14. Choi, K.; Bilich, A.; Larson, K.M.; Axelrad, P. Modified sidereal filtering: Implications for high-rate GPS positioning. Geophys. Res. Lett. 2004, 31, L22608. [CrossRef]

15. Chang, G.; Chen, C.; Yang, Y.; Xu, T. Tikhonov Regularization Based Modeling and Sidereal Filtering Mitigation of GNSS Multipath Errors. Remote Sens. 2018, 10, 1801. [CrossRef]

16. Bock, Y.; Nikolaidis, R.M.; de Jonge, P.J.; Bevis, M. Instantaneous geodetic positioning at medium distances with the Global Positioning System. J. Geophys. Res. 2000, 105, 28223-28253. [CrossRef]

17. Bock, Y.; Prawirodirdjo, L.; Melbourne, T.I. Detection of arbitrarily large dynamic ground motions with a dense high-rate GPS network. Geophys. Res. Lett. 2004, 31, L06604. [CrossRef]

18. Atkins, C.; Ziebart, M. Effectiveness of observation-domain sidereal filtering for GPS precise point positioning. GPS Solut. 2016, 20, 111-122. [CrossRef]

19. Alber, C.; Ware, R.; Rocken, C.; Braun, J. Obtaining single path phase delays from GPS double differences. Geophys. Res. Lett. 2000, 27, 2661-2664. [CrossRef]

20. Ragheb, A.E.; Clarke, P.J.; Edwards, S.J. GPS sidereal filtering: Coordinate-and carrier-phase-level strategies. J. Geod. 2007, 81, 325-335. [CrossRef]

21. Zhong, P.; Ding, X.; Yuan, L.; Xu, Y.; Kwok, K.; Chen, Y. Sidereal filtering based on single differences for mitigating GPS multipath effects on short baselines. J. Geod. 2010, 84, 145-158. [CrossRef]

22. Moore, M.; Watson, C.; King, M.; McClusky, M.; Tregoning, P. Empirical modelling of site-specific errors in continuous GPS data. J. Geod. 2014, 88, 887-900. [CrossRef]

23. Shi, Q.; Dai, W.; Zeng, F.; Kuang, C. The BDS Multipath Hemispherical Map Based on Double Difference Residuals and Its Application Analysis. In China Satellite Navigation Conference (CSNC) 2016 Proceedings: Volume I; Sun, J., Liu, J., Fan, S., Wang, F., Eds.; Lecture Notes in Electrical Engineering; Springer: Singapore, 2016; Volume 388.

24. Dong, D.; Wang, M.; Chen, W.; Zeng, Z.; Song, L.; Zhang, Q.; Cai, M.; Cheng, Y.; Lv, J. Mitigation of multipath effect in GNSS short baseline positioning by the multipath hemispherical map. J. Geod. 2016, 90, 255-262. [CrossRef]

25. Zheng, K.; Zhang, X.; Li, P.; Li, X.; Ge, M.; Guo, F.; Sang, J.; Schuh, H. Multipath extraction and mitigation for high-rate multi-GNSS precise point positioning. J. Geod. 2019, 93, 2037. [CrossRef]

26. Zheng, K.; Zhang, X.; Li, X.; Li, P.; Chang, X.; Sang, J.; Ge, M.; Schuh, H. Mitigation of Unmodeled Error to Improve the Accuracy of Multi-GNSS PPP for Crustal Deformation Monitoring. Remote Sens. 2019, 11, 2232. [CrossRef]

27. Ye, S.; Chen, D.; Liu, Y.; Jiang, P.; Tang, W.; Xia, P. Carrier phase multipath mitigation for BeiDou navigation satellite system. GPS Solut. 2015, 19, 545-557. [CrossRef]

28. Wang, Z.; Chen, W.; Dong, D.; Zhang, C.; Peng, Y.; Zheng, Z. An Advanced Multipath Mitigation Method Based on Trend Surface Analysis. Remote Sens. 2020, 12, 3601. [CrossRef]

29. Elósegui, P.; Davis, J.L.; Jaldehag, R.T.K.; Johansson, J.M.; Niell, A.E.; Shapiro, I.I. Geodesy using the Global Positioning System: The effects of signal scattering on estimates of site position. J. Geophys. Res. 1995, 100, 9921-9934. [CrossRef]

30. Liu, J.; Ge, M. PANDA software and its preliminary result of positioning and orbit determination. Wuhan Univ. J. Nat. Sci. 2003, 8, 603-609. [CrossRef]

31. Shi, C.; Zhao, Q.; Geng, J.; Lou, Y.; Ge, M.; Liu, J. Recent development of PANDA software in GNSS data processing. In The International Society for Optical Engineering, Proceedings of the International Conference on Earth Observation Data Processing and Analysis (ICEODPA), Wuhan, China, 28-30 December 2008; Li, D., Gong, J., Wu, H., Eds.; SPIE: Bellingham, WA, USA, 2008; Volume 7285, p. 72851S. 